\title{
The State of Fashion Design Pedagogy: The Roles of Students and Instructors
}

\author{
Katelyn Schmidt, Jill Zarestky \\ Colorado State University \\ Colorado State University \\ Kate.Schmidt@colostate.edu
}

\begin{abstract}
:
Over the last three decades, design has experienced foundational change as new technologies, changing consumer preferences, and globalization have set an unlimited platform for creativity and the exchange of ideas and products. Grounded in university fashion design degree programs and principles of adult education, the purpose of this work is to promote progressive thinking in education in the discipline of fashion design and to present a fresh take on corresponding teaching methods. The consumer and product industry requires graduates who have the knowledge and ability to occupy space in all three roles, as problem solvers, artists, and design thinkers. Structural change must be implemented in the creative education system in order to produce professionals with adaptive skillsets who have the ability to occupy multiple roles and engage creatively with broader contexts.
\end{abstract}

Keywords: Fashion Design, Pedagogy, Sustainability, Collaboration 


\section{The State of Fashion Design Pedagogy: The Roles of Students and Instructors}

Over the last three decades, fashion design has experienced foundational change as technologies, consumer preferences, and globalization have transformed the exchange of ideas and products. Fashion pedagogy should mirror this change by producing designers with adaptive skillsets who are able to engage creatively in different roles: as problem solvers, design thinkers, and artists. The world of fashion is becoming more interconnected; the percentage of American clothing that is made in the USA has been in sharp decline since 1965, plummeting from $95 \%$ to $5 \%$ (Pinkerson \& Levin, 2009). The globalization of the fashion industry has lessened the degree to which manufacturing is a part of the designer's role. The nature of fashion design has shifted from a vocational trade resulting in an object to a methodology with research and conceptual applications, where analytical thinking is the primary objective (Wolff \& Rhee, 2009).

Impacting local and global economies, the environment, and world culture, fashion design's changing nature underscores the importance of a shift in teaching methodology. Future fashion design pedagogy should mirror industry changes; successful teaching will emphasize design theory, design research, faculty and student mentorship, and an increased awareness of sustainability and technology innovation (Faerm, 2012).

Additionally, industry and academia inform each other, underscoring the need for design teaching to break out of the traditionally established silos and boundaries. While methodologies employed in undergraduate fashion design programs have been discussed in the literature, there is no comprehensive overview of the intricacies of fashion design pedagogy. Available publications concerning fashion design teaching methodologies are fragmented and lack a thorough review of the academic environment.

The first step to advancing fashion design education is simply understanding where we currently stand in the practice. This conceptual review captures the current state of teaching in creative disciplines by providing an overview of design education, the role of educators and students, and identified challenges. This work intends to capture that current state by providing an overview of fashion design education, the role of fashion design educators and identified challenges in apparel design pedagogy.

\section{What is Fashion Design Education?}

Core Fashion Design courses include Beginning Textiles, Color and Design Principles, Cultural Aspects of Dress, and Fashion Theory (Laughlin \& Kean, 1995). More abstract courses, such as Pattern Drafting and Grading, Functional Clothing Design, Advanced Apparel Design, and Fashion Illustration increase in frequency as students and faculty increase in number (Laughlin \& Kean, 1995). Curriculum in textiles and apparel courses is increasingly influenced by the fashion industry's needs as future employers, not the attainment of a "cogent, integrated body of knowledge" (Laughlin \& Kean, 1995, p.186).

Fashion design education occupies a unique balance between commerce and art, creating a tension between ideals and purpose. Art and design education is often encouraged to become more responsive and vocational, in an effort to prepare students for industry and business. Traditionally, design education has been guided by the premise, "learn by doing" where students log long hours in the studio focused on largely repetitive and labor-intensive design work. According to Lovinski, 
undergraduate fashion education should encourage conceptual and innovative design thinking through the use of maker's spaces and interdisciplinary practice labs (2009). It is important that students learn apparel design as a collaborative practice. Evolving design education encourages students to cross disciplinary boundaries and traditional barriers, allowing them to learn new skills, understand complex issues, and be leaders in change (Faerm, 2012).

According to Dorst and Reymen (2004), this learn-by-doing approach often leaves students without the ability to verbalize their new knowledge, which can be balanced with the addition of verbal and cognitive underpinning in design pedagogy. The undergraduate fashion design studio is moving from the physical garment as the primary objective to a more expansive focus on process and cognition (Gully, 2010). Gully (2010) suggests that contemporary fashion design pedagogy is cognitive in nature, despite the previous connotations of the discipline being largely trade centered. Art and design disciplines require divergent and innovative pedagogical approaches to inspire and energize students (Agarwal, 2018). The ideology of becoming an "artist" in design school is often undermined, yet artistry is the romantic vision that epitomizes design school itself (Frith \& Horne, 1987). Arguably, the romantic lens through which many view art and design is integral to its survival as a discipline.

\section{Roles of Student Fashion Designers}

Curriculum and instructional approaches correspond to the overall perception of the student's role. Modern fashion design pedagogies vary in how they define the fundamental role of the designer and design student. The student designer is often perceived as a problem solver, artist, or design thinker. The fashion industry remains situated as a process driven by human activity, underscoring the fundamental need for collaboration and mutuality in the design system (Williams \& Fletcher, 2010). The student designer of the future is encouraged to take on an interdisciplinary role. The design venture is strengthened by an understanding between designers, makers, buyers, and people of different geographical locations and cultures (Williams \& Fletcher, 2010). To succeed as designers in a dynamic and expeditious future, fashion students would be benefitted by a curriculum that encourages them to collaborate and communicate across disciplines while gaining a greater sense of the world.

\section{Student Fashion Designers as Problem Solvers}

Many contemporary educators view the fashion designer as a problem solver, who generates ideas that become solutions in our world (Lovinski, 2009). Therefore, it is the role of educators in the field to teach students how to come up with solutions through multidisciplinary approaches. According to Ambasz (1972), the first approach to design teaching is apparel design as a problem-solving activity, requiring the formulation of physical solutions to encountered problems. The student designer encounters countless problems in the design process including fit, usability, and versatility.

According to Oh (2017), problem solving can be defined as a creative process that utilizes both divergent and convergent cognition through three stages: transformation, clarification, and implication. In the transformation stage, the student explores ideas and formulates solutions before moving on to the clarification stage, where they are formulating challenges and exploring their overall vision (Puccio et al., 2007). In the third stage, the student designer is formulating a plan and exploring the acceptance of their solution (Puccio et al., 2007). Student designers are taught to take a cause-and-effect approach, where design is understood as problem solving at its core (Dorst \& Reymen, 2004). In each stage of the process, divergent thinking manifests as an extensive search for 
ideas, whereas convergent thinking is the selection of workable solutions through evaluation of alternatives (Oh, 2017).

Creative problem solving is often unintuitive because it requires a specific cognitive skillset centered on the generation of ideas and the refinement of those ideas into useful solutions (Oh, 2017). Teaching the problem-solving process in apparel design is the key to successful innovation and the realization of student creative potential.

\section{Student Fashion Designers as Artists}

The apparel design student in the artist's role uses decision making, information-gathering, experimental, and evaluative processes to metamorphosize a physical product guided by an expressive concept (Lee, 2006). Kupferberg (2006) describes the artist's main role as expression of deep feelings through authenticity and empathy. It is argued that fashion design school should be anchored in artistry and creative vision (Skjold, 2008). It is through the artistic role that students are encouraged to create meaningful new forms and display "thought leadership" by translating artistic ideas into visual objects (Kucharska \& Mikołajczak, 2018).

Fashion design exists as a paradox, occupying space between the artistic endeavour and the entrepreneurial and industrial world. Creative artistry and the generation of new ideas can be described through contemporary stage models, which are often formulated through Wallas' (1926) foundational work that describes the stages of artistic development: preparation, incubation, ideation, selection, and execution.

Fashion design is undeniably an artistic profession, structured around creative projects and requiring flexible thinking (Yagoubi \& Tremblay, 2016). Despite this, perceiving student designers as strictly artists impairs their development. The economy of the future will require that students understand how to create value and newness in the changing world, requiring artistry in addition to problem solving and design thinking.

\section{Student Fashion Designers as Design Thinkers}

Brown (2009) defines design thinking as, "a discipline that uses the designer's sensibility and methods to match people's needs with what is technologically feasible and what a viable business strategy can convert into customer value and market opportunity" (p.86). The objective of design thinking is to nurture a growth mindset where innovation is the key to overcoming future and current industry challenges (Brown \& Kātz, 2019). Unpacking the meaning and application of design thinking is valuable because it helps us identify a new focus for contemporary apparel design curriculum (Bailey, 2010).

Design thinking can also be described as reflection-in-action, and it is one of the most integral skills design students learn (Bailey, 2010). Encouraging students to engage in reflection during the design process may enable them to deviate from habitual methods, engender flexibility in thinking and process, and develop more divergent design work (Mezirow, 1991). According to Coorey, the ability to reflect on your own learning and work, and to adjust in action, has been identified as one of the key determinants of successful design thinking (2016).

Teaching fashion design students as solely design thinkers, artists, or problem-solvers hinders inspiration, underscoring the need for design education that recognizes students as occupying space in all three roles. Fashion design education that values the various perspectives of students attempts to bridge the gap between thinking and doing, while pushing students to not simply create 
aesthetically pleasing garments, but to capture consumers with complex product narratives (Faerm, 2015).

\section{The Role of Fashion Design Educators}

Educators' shared objective is to elucidate the "known" of their discipline, to foster enthusiasm for the unknown, and to impart education as a true form of optimism, represented not as a specific known fashion design product, but an evolution in design intelligence (Bailey, 2010). Educators are charged with encouraging craft-based skills with the objective of design innovation ability in mind. It is essential that fashion design undergraduate programs encourage more than technical skill development by taking a holistic approach (The Fashion Condition, 2014). Fashion illustration, patternmaking, draping, and sewing have great pedagogical value for aesthetic understanding, spatial learning, and visual thinking, the true educational accomplishments for the student designer (Lovinski, 2009).

In the fashion design discipline of academics, curriculum orientation and instructors' roles vary widely (Chen \& Chen, 2016). Most current fashion design programs view the teacher as working under the ideology of fashion as technology-based, with art as the secondary element (Chen \& Chen, 2016). Other roles of the fashion instructor revolve around teaching artistic design theories and the practices of craft to students, as well as the perspective of the teacher as preparing the student for industry through cultivation of professional and practical skills (Chen \& Chen, 2016). Instructors of apparel design typically take on roles that centralize on theory, design methodology, or industry engagement (Faerm, 2015).

A teacher who identifies with a theoretical role bases instruction on overall academic and creative development through emphasizing humanistic studies and a cultural-historical approach, where fashion exists as a cultural experience in a social and historical context (Skjold, 2008). Gully suggests contemporary fashion design pedagogy is cognitive in nature, despite the previous connotations of the discipline being largely trade-centered (2010). Successful apparel design instructors would benefit from bridging the gap between theory and practice. "It is one thing to have an idea and another thing to make that idea concrete and real" (Breslin \& Buchanan, 2008, p. 36). As apparel design has transitioned from a trade-focused to an application-based methodology, fashion instructors may shift in role from facilitator of object to that of process or system (Faerm, 2015). Design instructors should foster design thinking to the same degree and rigor as design making.

\section{Current and Future Challenges}

To effectively question the current model of fashion design education, we can identify the specific problems that reside within the system. Over the last three decades, design has experienced foundational change. This is largely the result of evolving technology and changing consumer preferences. Technology and globalization have set an unlimited platform for business exchange; our societies are now "closer", and designers can produce and share their goods around the world (Faerm, 2015). Fashion design graduates must have a knowledge base of 3D technologies, as the industry is shifting towards simulated advanced product development. Additionally, designers' approach to product creation now centers on the user, with a need for genuine involvement and empathy for the ultimate consumer (D'Andrea \& Teli, 2010). 


\section{The Sustainability Challenge}

The pace of apparel production and consumption is at an all-time high; Consumers now demand four times the number of garments that they did in 1980 (Seigel, 2011). Due to the consumer sense of abundance impelled by high rates of production, consumption, and disposal, design is no longer driven by need (Van der Velden, 2006). It will take ingenuous designers with the ability to innovate and think divergently to transform an economic global model that centers on continual consumption (Williams, 2019).

It would be valuable for fashion design students to not only learn the skills and information necessary to succeed in the current fashion industry, but to amass knowledge that will allow them to revamp and improve the industry (Towers, 2005). It is integral that design schools explore new ways of teaching sustainable design to promote greater change. For example, 3D software is useful in teaching zero waste fashion design techniques as well as 2D pattern-cutting, waste reduction, and exploring new design workflows (McQuillan, 2020). The magnitude of the industry's devastation of the natural environment, the loss of biodiversity, and furtherance of modern-day slavery cannot be ignored in the academic sphere (Williams, 2019).

\section{The Future of Fashion Design Pedagogy}

As micro- and macro-economic changes ensue within the fashion industry, design students are encouraged to learn to view the system through a broader lens (Faerm, 2015). According to Faerm (2015), design pedagogy will move toward a focus on design thinking and the conceptual process. Design, once centered on the "made" artifact, is now moving towards a proactive, social, and outcome-based practice (Rowe, 2020). With an oversaturated market, consumers seek much more than physical product, rather something that carries deep emotional meaning (Faerm, 2015). The role of designers has shifted to focus on the outcomes and impacts of creative work. As such, it would be beneficial to teach emerging designers in a manner that reflects the inherent change in design as a discipline, and the roles that we perceive student designers as operating within. The everchanging fashion industry requi1res graduates who have the knowledge and ability to occupy space in all three roles. Successful designers of the future will be able to operate as problem solvers, artists, and design thinkers, and the way in which we teach design students must mirror this interdisciplinarity. 


\section{References}

Agarwal, S. (2018). Innovation Arabia 11. In The Application of Lin's Conceptual Framework of Creative Pedagogy in Fashion Design Education (pp. 1-246). Index Exhibitions.

Bailey, S. (2010). Towards a Critical Faculty. Office for Contemporary Art Norway, 1-34.

Chen, W., \& Chen, J. L. (2016). Teaching Reform of Clothing Drafting Course in the Major of Fashion Design. Proceedings of 2016 5th International Conference on Social Science, Education and Humanities Research. https://doi.org/10.2991/ssehr-16.2016.349

Coorey, J. (2016). Active Learning Methods and Technology: Strategies for Design Education. International Journal of Art \& Design Education, 35(3), 337-347. https://doi.org/10.1111/iade.12112

D'Andrea, V., \& Teli, M. (2010). Teaching participatory design. Proceedings of the 11th Biennial Participatory Design Conference on - PDC '10, 166-169. https://doi.org/10.1145/1900441.1900486

Dorst, K., \& Reymen, I. (2004). International Engineering and Product Design Education Conference. In Levels of Expertise in Design Education (pp. 1-8). Delft. https://www.designsociety.org/downloadpublication/19588/levels of expertise in design educa tion.

Faerm, S. (2012). Towards a future pedagogy: the evolution of fashion design education. International Journal of Humanities and Social Science, 2(23), 210-219.

Faerm, S. (2015). Building best practices for fashion design pedagogy: Meaning, preparation, and impact. Cuadernos del Centro de Estudios de Diseño y Communicatión, 16(53), 189-213. https://doi.org/10.18682/cdc.vi53.1636

Frith, S., \& Horne, H. (1987). Art into pop (1st ed.). Methuen.

Gully, R. (2010). Cognition and process vs. design artifact in fashion design pedagogy. Melbourne Cumulus Working Papers, Publication Series G. Aalto University.

Kucharska, W., \& Mikołajczak, P. (2018). Personal branding of artists and art-designers: Necessity or desire? Journal of Product \& Brand Management, 27(3), 249-261. https://doi.org/10.1108/jpbm01-2017-1391

Kupferberg, F (2006). Kreative tider: At nytænke den pædagogiske sociologi. HansReitzels forlag,

Laughlin, J., \& Kean, R. C. (1995). Assessment of textiles and Clothing academic programs in the United States. Clothing and Textiles Research Journal, 13(3), 184-199. https://doi.org/10.1177/0887302×9501300305

Lee, B. D. (2006). A Study on Fashion Design Pedagogy for the Development of Creativity With Emphasis on Intuition. Journal of Korean Society of Clothing and Textiles, 30(3), 487-496.

Lovinski, N. (2009). What is good fashion design? Design Principles and Practices, 3(6), 89-98. https://doi.org/10.18848/1833-1874/CGP/v03i06/37786

Mezirow, J. (1991). Transformative dimensions of adult learning. Jossey-Bass..

Pinkerson, D. \& Levin, M. (Producers), \& Levin, M. (Director). (2009). Schmata: rags to riches to rags [Motion picture]. United States: Home Box Office Documentary Films.

Rowe, A. (2020). Participatory Action Research and design pedagogy: Perspectives for design education. Art, Design \& Communication in Higher Education, 19(1), 51-64.

https://doi.org/10.1386/adch 000131

Seigel, L. (2011, May 8). Why fast fashion is slow death for the planet. The Guardian, 35.

Skjold, E. (2008). Fashion research at design schools. Designskolen Kolding. 
Towers, J. (2005, July). Sustainable design. Print. [Online] Available:

http://www.europeanoutdoorgroup.com/downloads/sustainabledesign/Sustainabledesign.pdf

Williams, D. (2019) What's Going On? A Discourse in Fashion, Design, and Sustainability, Fashion

Practice, 11(3), 283-290. DOI: 10.1080/17569370.2019.166223

Williams, D., \& Fletcher, K. (2010). Shared talent: An exploration of the potential of the 'Shared Talent' collaborative and hands on educational experience for enhanced learning around sustainability in Fashion Practice. Sustainability in Design: Now! Challenges and Opportunities for Design Research, Education and Practice in the XXI Century. https://core.ac.uk/display/30314457.

Wolff, L., Rhee, J. (2009, May). Is design the new liberal arts? Re: D, 26(6), 9-13. 
Author Bios:

Kate Schmidt, M.S Design and Merchandising, is a doctoral student in the Ph.D. Education, Equity, and Transformation program at Colorado State University. Her research interests center on education strategies and methodologies in fashion design and creative disciplines.

Jill Zarestky, PhD, is an assistant professor of Adult Education and Training in the Colorado State University School of Education. Her research interests focus on adult and STEM education and issues of conservation, sustainability, and globalization. 